\title{
Naloxone as a trigger to identify opioid-related adverse events in pediatric intensive care units
}

\section{Abstract}

Objective: this study had the objective to identify opioid-related Adverse Drug Events (ADE) with naloxone as a trigger and evaluate the patterns of naloxone administration in hospitalized children as well as verify the report of these ADE to the hospital's pharmacovigilance department. Methods: a retrospective review of electronic medical records was conducted with records of pediatric patients who received naloxone from January $1^{\text {st }}, 2015$ to June $30^{\text {th }}, 2016$. Descriptive statistics and analysis of Variance (ANOVA) followed by Tukey's test were performed to analyze the results ( $\mathrm{P}<0.05$ was considered statistically significant). The study was conducted in a tertiary children's hospital in Paraná, Brazil. Results: we found 58 opioid-related ADE (3.2 events/month) and an underreporting rate of $93 \%$ at the hospital. All of the events occurred in Intensive Care Units (ICU) while most of the patients were female (51.7\%) and infants (from 1 month old to 24 months old) (51.7\%) inside the Cardiac ICU (63.8\%). Fentanyl was the most prescribed opioid (66.2\%); apnea (29.31\%) and insaturation (20.69\%) were the most reported symptoms during the ADE. All opioid-related ADEs caused temporary harm to the patients and required intervention. However, only $2.8 \%$ of the patients presented ADE by opioid intoxication. The opioid-related ADE were not influenced by opioid types, age groups or patients' diseases. Conclusions: these findings showed a higher incidence of opioid-related ADE inside the Cardiac ICU among infants and a significant underreporting rate of these ADE to the pharmacovigilance department. Our study strengthens the importance of the human factor as a possible cause of $\mathrm{ADE}$ in pediatric patients, as well as the challenge to manage patient's safety in pediatric institutions.

Keywords: adverse drug events, intensive care, naloxone, opioids, pediatric.

\section{Naloxona como gatilho para identificar eventos adversos com opióides em unidades de terapia intensiva pediátricas}

\section{Resumo}

Objetivo: identificar e classificar Eventos Adversos a Medicamentos (EAM) relacionados a opióides em hospital pediátrico, utilizando naloxona como gatilho, e verificar a incidência de notificação destes eventos ao serviço de farmacovigilância hospitalar. Métodos: estudo descritivo, documental, quantitativo e retrospectivo, realizado em hospital pediátrico em Curitiba/PR. A coleta de dados ocorreu com revisão de prontuário dos pacientes que receberam naloxona entre janeiro de 2015 a junho de 2016. Foram realizadas análises descritivas e Análise de Variância (ANOVA) seguida de teste de Tukey (valor $\mathrm{p}<0.05$ considerado estatisticamente significativo). Resultados: foram encontrados 58 EAM relacionados a opióides (3.2 eventos/mês) e taxa de subnotificação de $93 \%$. Todos os eventos ocorreram em Unidades de Terapia Intensiva (UTI); a maioria dos pacientes era do sexo feminino (51.7\%), lactente (51.7\%) e hospitalizada em UTI Cardíaca (63.8\%). Fentanil foi o opióide mais prescrito (66.2\%); apneia (29.31\%) e insaturação (20.69\%) foram os sinais mais relatados para o uso de naloxona. Todos os EAM com opióides causaram danos temporários aos pacientes e precisaram de intervenção. Porém, apenas $2.8 \%$ dos pacientes apresentaram o evento devido à intoxicação por opióide. Os EAM não foram influenciados pelo tipo de opióide, grupo etário ou tipo de patologia dos pacientes. Conclusão: houve incidência maior de EAM relacionados a opióides na UTI Cardíaca e um alto índice de subnotificação destes eventos ao serviço de farmacovigilância. Este estudo destaca a importância do fator humano como possibilidade de causa de EAM em pacientes pediátricos e o desafio de gerenciar a segurança do paciente em instituições de saúde pediátricas.

Palavras-chave: eventos adversos a medicamentos, unidade de terapia intensiva, naloxona, opióides, pediatria.

DOI: $10.30968 /$ rbfhss.2019.102.0411

ISSN online: $2316-7750$

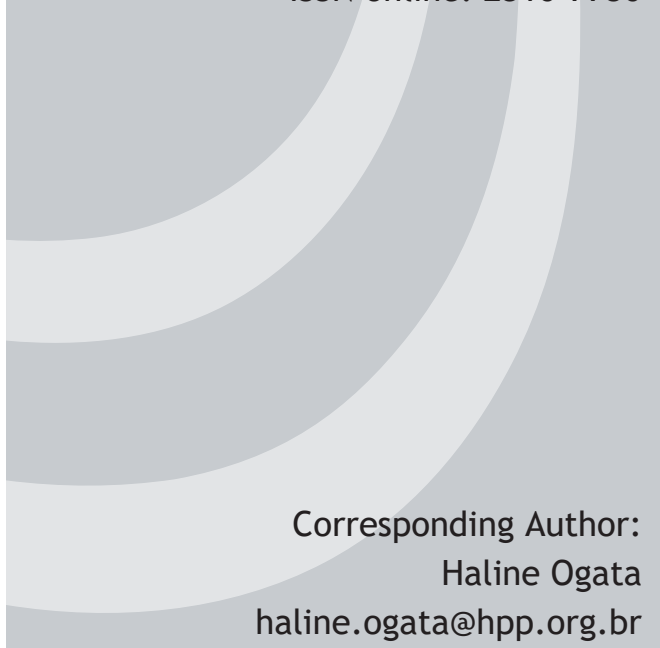




\section{Introduction}

Adverse Drug Events (ADEs) are damages caused by a drug intervention and may be caused by the administration of the drug at an inappropriate or therapeutic dose. ${ }^{1}$ The occurrence of ADEs in hospitals affects patient safety and is one of the most common problems in health care institutions. ${ }^{2,3}$ Its frequency ranges from 1.7 to 51.8 events/ 100 hospitalizations, and most of these events could be prevented.

ADEs can be caused by drug intoxication if associated with errors in prescribing, handling, dispensing or administration. ${ }^{6}$ Thus, there are drugs considered as High Vigilance (HV) because they have a significant potential to cause harm to the patient, such as the opioid class, which includes morphine, fentanyl, methadone, among others. ${ }^{7,8}$

Opioids are opium-derived analgesics used for sedation and pain control, and are related to ADEs like deep sedation and respiratory depression..$^{9-11}$ These events are clinically relevant, especially in children. ${ }^{10}$

Early or advanced age, opioid exposure time, and cardiovascular and respiratory diseases are known to be important factors to consider in opioid-related ADEs. ${ }^{10-12}$ In addition, it is estimated that most inpatients receive treatment with these medications. Of the total patients, $0.3 \%$ to $0.6 \%$ have serious adverse events associated with this type of analgesic. ${ }^{11,13}$

In cases of opioid overdose, the naloxone antagonist is used to counteract its effects in patients. ${ }^{14}$ Thus, the use of naloxone may be a flag or trigger for possible opioid ADEs, described in the "Global Trigger Tool" methodology. ${ }^{15}$ The purpose of this tool is to identify adverse events through a weekly review of randomized medical records. ${ }^{16}$

Although opioids are classified as HV and are commonly related to ADEs, there are few publications on opioid toxicity in children. ${ }^{89}$ Thus, studies on opioid $\mathrm{ADEs}$ are relevant in the pediatric area, considering that children are more vulnerable than adults, especially patients admitted to intensive care units (ICUs).10,11,15

The aim of this study was to identify and classify opioid-related ADEs using naloxone as a trigger, as well as to verify the incidence of reporting these events to the hospital pharmacovigilance service.

\section{Methods}

\section{Type and place of study}

A descriptive, documentary, quantitative and retrospective study conducted in a high complexity pediatric hospital in Curitiba/PR.

\section{Ethical aspects}

This study complied with Resolution No. 466/12 of the National Health Council and was approved by the Research Ethics Committee (Comitê de Ética em Pesquisa, CEP) of the research institution, under CAAE number: 55400416.2.0000.5580.

\section{Samples}

The sample refers to all patients who used naloxone from January 2015 to June 2016 (18 months). The medical chart numbers were obtained through an electronic report issued by the hospital pharmacy dispensing service, where the MV2000 electronic medical record system is used.

Data collection was performed through the review of the electronic medical records of the selected patients, that is, those who used naloxone during their hospitalization period.

Due to the characteristics of the events reported in the medical records and to the formal indication on the use of naloxone, all naloxone administration was associated with the occurrence of an opioid-related adverse event. ${ }^{14}$ Exclusion criteria were the following: a) prescription of opioids only under medical order or if necessary; b) use of naloxone in the operating room.

\section{Data collection}

All data were collected on the MV2000 system and stored in a Microsoft Excel $^{\circ}$ spreadsheet. The variables included the patients' demographic characteristics (gender, age, type of pathology, length of hospitalization, whether undergoing surgery or not, symptoms that caused naloxone use), and information on opioid prescriptions (opioid type, route and frequency of administration, dose classification).
Patients were classified by age group: neonates ( 0 to 28 days), infants ( 29 days to 24 months), children (>24 months to 12 years old) and adolescents (>12 to 18 years old).

Opioid-related ADEs were classified into intoxication (when the opioid is prescribed in overdose according to the hospital's protocol); or adverse reaction (occurring with therapeutic dose opioid). ${ }^{17}$ For this purpose, the doses prescribed for each opioid were compared with the doses recommended by the hospital's protocols (10-60 mcg/kg/hour morphine; $1-10 \mathrm{mcg} / \mathrm{kg} / \mathrm{hour}$ fentanyl; $0.1 \mathrm{mg} / \mathrm{kg} /$ dose methadone).

To categorize the harm to the patient caused by the event, the adapted version of the North American NCC MERP (National Coordinating Council for Medication Error Reporting and Prevention) Index was used for error categorization of medications. ${ }^{18}$ The number of opioid-related ADEs that were formally reported at the institution was collected through the hospital's reporting system.

\section{Data analysis}

Data analysis was performed with the $\mathrm{R}$ statistical program (R Core Team 2016). Data was analyzed in parametric and nonparametric variables with the following statistical analyses: the ANOVA (Analysis of Variance) method for comparison among multiple groups and the Tukey method for the comparison of each two groups of data. The p value $<0.05$ was considered statistically significant.

\section{Results}

\section{Study population and opioid use}

58 opioid-related ADEs were found in the 18-month period, which corresponds to an average of 3.2 events/month or 3 events per 1000 admissions. As each patient presented only one $\mathrm{ADE}$, the number of $\mathrm{ADES}(\mathrm{N}=58)$ is the same as the number of patients $(\mathrm{N}=58)$. Table 1 shows that the mean age of these patients was 2.81 years old, $50 \%$ of whom were hospitalized for up to 22.5 days and had an $\mathrm{ADE}$ within 6 days after admission to the hospital.

Table 1. Age of the patients, length of stay and number of days from admission to occurrence of opioid-related $\mathrm{ADE}(\mathrm{N}=58)$

\begin{tabular}{lcccc}
\hline Variables & Mean & Median & Interval & SD \\
\hline Age (years old) & 2.81 & 0.5 & $0^{*}-17$ & 4.41 \\
Hospitalization (days) & 41.78 & 22.5 & $6-246$ & 46.81 \\
Time to ADE (days) & 15.09 & 6 & $1-114$ & 24.04 \\
\hline
\end{tabular}

Abbreviations: ADE, Adverse Drug Event; SD, Standard Deviation.

*3 days of life

The information on opioid prescriptions and other patient characteristics is presented in Table 2. Cardiovascular problems were observed in $67.2 \%$ of the patients, which is associated with the place most events occurred: Cardiac ICU (65.5\%). All opioid-related ADEs found in the study occurred in the ICU (Table 2)

Most patients received only one opioid (morphine, fentanyl or methadone) (77.6\%), while $22.4 \%$ of the patients received treatment with two opioids (fentanyl + morphine or fentanyl + methadone), with 71 prescriptions prepared for all the 58 patients.

Fentanyl was the most commonly prescribed opioid (66.2\%), continuous infusion was the preferred dose $(64.8 \%)$ with predominance of intravenous (IV) administration (90.1\%) (Table 2), corroborating the characteristics of continuous sedation and critical condition of the ICU patients.

The medical records indicated that $97.2 \%$ of the opioids were prescribed at a pediatric therapeutic dose (Table 2), suggesting that most patients had an adverse drug reaction or that there was an error in the administration of these opioids, as all patients required naloxone. Only $2.8 \%$ of the opioids were prescribed in medical records above the therapeutic dose, indicating that the $\mathrm{ADE}$ occurred due to opioid poisoning. 
Table 2. General characteristics of the patients $(\mathrm{N}=58)$ and information on opioid use $(\mathrm{N}=71)$

\begin{tabular}{|c|c|}
\hline Characteristics of the patients & $\mathrm{N}(\%)$ \\
\hline \multicolumn{2}{|l|}{ Gender } \\
\hline Female & $30(51.7)$ \\
\hline Male & $28(48.3)$ \\
\hline \multicolumn{2}{|l|}{ Age group } \\
\hline Neonate & $9(15.5)$ \\
\hline Infant & $30(51.7)$ \\
\hline Child & $16(27.6)$ \\
\hline Teenager & $3(5.2)$ \\
\hline \multicolumn{2}{|l|}{ Pathology type } \\
\hline Cardiovascular & $39(67.2)$ \\
\hline Gastrointestinal & $6(10.3)$ \\
\hline Neurological & $4(7.0)$ \\
\hline Hematologic & $3(5.2)$ \\
\hline Respiratory & $3(5.2)$ \\
\hline Orthopedic & $2(3.4)$ \\
\hline Oncologic & $1(1.7)$ \\
\hline \multicolumn{2}{|l|}{ Inpatient unit } \\
\hline Cardiac ICU & $38(65.5)$ \\
\hline Surgical ICU & $11(18.9)$ \\
\hline General ICU & $5(8.6)$ \\
\hline Neonatal ICU & $4(7.0)$ \\
\hline \multicolumn{2}{|l|}{ Surgical procedure } \\
\hline Yes & $48(82.8)$ \\
\hline No & $10(17.2)$ \\
\hline \multicolumn{2}{|l|}{ Opioid usage information } \\
\hline \multicolumn{2}{|l|}{ Opioid type } \\
\hline Fentanyl & $47(66.2)$ \\
\hline Morphine & $17(23.9)$ \\
\hline Methadone & $7(9.9)$ \\
\hline \multicolumn{2}{|l|}{ Route of administration } \\
\hline Intravenous (IV) & $64(90.1)$ \\
\hline Enteral & $7(9.9)$ \\
\hline \multicolumn{2}{|l|}{ Administration frequency } \\
\hline Continuous infusion & $46(64.8)$ \\
\hline Intermittent infusion & $25(35.2)$ \\
\hline \multicolumn{2}{|l|}{ Dose rating } \\
\hline Therapy & $69(97.2)$ \\
\hline Overdose & $2(2.8)$ \\
\hline
\end{tabular}

Abbreviation: ICU, Intensive Care Unit.

\section{Opioid-related Adverse Drug Event (ADE)}

The patients presented the ADE after a mean of 4.21 days since the beginning of the opioid treatment. In addition, the median, that is, $50 \%$ of the patients, had the event after one day of treatment (Table 3 ).
Table 3. Time (days) from start of opioid use to the occurrence of the ADE by type of opioid, age group and type of pathology

\begin{tabular}{|c|c|c|c|c|c|}
\hline Variable & $\mathbf{N}$ & Mean & Median & Interval & SD \\
\hline \multicolumn{6}{|l|}{ Opioid type } \\
\hline All opioids & 71 & 4.21 & 1 & $0^{*}-66$ & 9.58 \\
\hline Fentanyl & 47 & 4.43 & 1 & $0^{*}-66$ & 10.94 \\
\hline Methadone & 7 & 10.29 & 7 & $4-28$ & 8.62 \\
\hline Morphine & 17 & 1.12 & 1 & $0^{*}-7$ & 1.76 \\
\hline \multicolumn{6}{|l|}{ Age group } \\
\hline Neonate & 9 & 4.67 & 2 & $0^{*}-25$ & 7.9 \\
\hline Infant & 30 & 6.83 & 1 & $0^{*}-66$ & 13.6 \\
\hline Child & 16 & 1.56 & 1 & $0^{*}-5$ & 1.7 \\
\hline Teenager & 3 & 2 & 0 & $0^{*}-6$ & 3.5 \\
\hline \multicolumn{6}{|l|}{ Pathology type } \\
\hline Cardiovascular & 39 & 6.28 & 1 & $0^{*}-66$ & 12.47 \\
\hline Gastrointestinal & 6 & 2.5 & 1.5 & $0^{*}-8$ & 3.08 \\
\hline Neurological & 4 & 0.5 & 0.5 & $0^{*}-1$ & 0.58 \\
\hline Hematologic & 3 & 3.67 & 5 & $0^{*}-6$ & 3.21 \\
\hline Respiratory & 3 & 0.67 & 1 & $0^{*}-1$ & 0.58 \\
\hline Orthopedic & 2 & 1 & 1 & $0^{*}-2$ & 1.41 \\
\hline Oncologic & 1 & 1 & 1 & NA & NA \\
\hline
\end{tabular}

The time from the beginning of the opioid treatment to the occurrence of the ADE was also calculated in days for each opioid type (fentanyl, methadone, morphine), each age group and each type of pathology separately, as shown in Table 3. For example, patients receiving methadone had the ADE within 4-28 days of starting the methadone treatment; in the case of infants, the period was longer, as this age group had an ADE between less than 24 hours and 66 days after the beginning of the opioid treatment (Table 3 ).

It is noteworthy that all variables had an $\mathrm{ADE}$ in less than 24 hours, except for patients receiving methadone (Table 3 ).

The results in Table 3 were also compared for each two types of opioid and for each two age groups (Table 4). However, there was no significant difference $(p>0.05)$ in this analysis. The same was observed after comparing the data to each two types of pathology (data not shown). This result indicates that the time for the occurrence of the opioid-related $\mathrm{ADE}$ was not influenced by the opioid type, the age group or the type of pathology of the patients.

Table 4. Time difference (days) from the beginning of opioid use to the occurrence of the $\mathrm{ADE}$ among opioid types and age groups

\begin{tabular}{lcc}
\hline Compared variables & Mean difference & Pvalue (Tukey) \\
\hline Opioid types & & \\
Methadone - Fentanyl & 5.86 & 0.2791 \\
Fentanyl - Morphine & 3.31 & 0.4317 \\
Methadone - Morphine & 9.17 & 0.0832 \\
Age groups & & \\
Infants - Neonates & 2.167 & 0.9480 \\
Teens - Neonates & 2.667 & 0.9810 \\
Children - Neonates & 3.104 & 0.8929 \\
Teens - Infants & 4.833 & 0.8719 \\
Children - Infants & 5.271 & 0.3753 \\
Children - Teens & 0.437 & 0.9999 \\
\hline
\end{tabular}

Abbreviation: ADE, Adverse Drug Event. 
The symptoms reported for naloxone use were apnea (29.31\%) unsaturation $(20.69 \%)$, bradycardia $(10.34 \%)$, hyporesponsiveness or deep sedation $(5.17 \%)$, cyanosis (5.17\%), breathing effort $(3.45 \%)$ and chest stiffness (1.73\%). There was incomplete information in 14 medical records analyzed (24.14\%), which did not contain any justification for the administration of naloxone, although this drug was prescribed to the patient.

The harm caused to the 58 patients with an ADE was categorized as "E" according to the adapted version of the North American NCC MERP index. This means that the events caused temporary harm to the patient, that is, non-permanent harm requiring intervention.

\section{Notification of an opioid-related ADE}

According to the official notification data of the hospital, during the survey period there were only 4 opioid-associated event notifications. All of them were related to methadone use and were considered sentinel events, as they involved a risk of severe harm to the patients. Considering the 58 opioid-related ADEs found in the study, this data corresponds to an underreporting rate of $93 \%$.

\section{Discussion}

This study used naloxone as a trigger and identified a mean of 3.2 opioid related ADEs per month. This data is similar to other studies involving ADEs and naloxone use in adult and pediatric patients. For example, Beaudoin et al found 2.02 events/month and Nwulu et al report 5.08 events/month, but both studies have evaluated the incidence of opioid ADEs in adults. ${ }^{19,20}$ Chidambaran et al. and Hasan et al. showed rates of 1.3 events/month and 5.4 events/month in children receiving naloxone, respectively. ${ }^{21,22}$

In addition, a value of 3 ADEs with opioids was found per 1000 hospital admissions, which is important for the Pharmacovigilance service. Considering the frequency of 1.7 to $51.8 \mathrm{ADEs} / 100$ hospitalizations found in the literature, ${ }^{4}$ this is a low but expected result, as this rate refers to all types of ADEs and not just to the opioid-related ones, as presented in this study.

Most children in the Hasan et al. study was female (55.1\%), and most patients in the study by Chidambaran et al. were in the postoperative period (71.05\%). ${ }^{21,22}$ In this study, similar values were found: $51.7 \%$ were female patients, and $82.8 \%$ had performed some surgical procedure (Table 2 ).

In the present study, $77.6 \%$ of the patients received treatment with only one type of opioid. This percentage is higher than the value presented by Yung et al. in adult patients (47\%). ${ }^{23}$ However, similarly to the study by Lee et al., ${ }^{24}$ the most prescribed opioids in this study were fentanyl (66.2\%) and morphine (23.9\%) (Table 2). IV was also identified as the most commonly used route of administration $(90.1 \%)$, a result similar to that presented by Beaudoin et al. $(93.2 \%)^{19}$.

In general, $\mathrm{ADEs}$ may be the result of an adverse reaction to the therapeutic dose or an error in prescribing, dispensing, manipulating or administering the drug, which may cause poisoning in the patients. ${ }^{5}$ Several studies indicate that almost $50 \%$ of the opioid errors occur during the administration step. ${ }^{25}$ Thus, although this study identified only $2.8 \%$ of the opioids prescribed in overdose (Table 2 ), the number of ADEs caused by opioid poisoning may be much higher, considering the possibility of errors in drug preparation, handling and administration.

The mean hospitalization time of the patients was 41.78 days (Table 1) This prolonged period of hospitalization may be related to the severe clinical conditions found in the ICU, where all ADEs in this study occurred. Similarly, Chidambaran et al. showed that $50 \%$ of the children receiving naloxone were admitted to an ICU. ${ }^{21}$ These data demonstrate the importance of careful care during opioid treatment in critically ill pediatric patients.

Among the age groups, more than half of the opioid ADEs were presented by infants $(51.7 \%)$ (Table 2), while children were the group that presented ADEs in the shortest period after the opioid treatment (mean of 1.56 days) (Table 3 ). These results demonstrate the epidemiological profile of hospital patients, who are mostly children under 5 years old, and reinforce that early age is relevant when considering opioid-related ADEs. ${ }^{10,15,21}$

In addition to age, cardiovascular and respiratory comorbidities are important factors to be examined in cases of ADEs with opioids. ${ }^{10,12,22}$ In the present study, $67.2 \%$ of the patients had some cardiovascular disease, which may cause more vulnerability when these patients have an ADE.

The results showed no statistical difference when opioid types, age groups, and pathology types were analyzed according to the number of days for the opioidrelated ADE to occur (Table 4). These data suggest that the time to the occurrence of the ADE was not influenced by these variables and that opioid treatment itself should be a reason for high attention in the care of critically ill pediatric patients. Thus, this study highlights the importance of the human factor in the management of medication administration, especially in children.

Several health institutions, including the hospital where this research was conducted, detect ADEs through voluntary reporting. However, only $10 \%$ to $20 \%$ of the events can be found this way, ${ }^{16}$ which may justify the high underreporting rate identified (93\%). In addition, this study demonstrated that half of the patients had the ADE in less than 24 hours after the opioid treatment (Table 3).

These results are highly relevant for improvements in the pharmacovigilance service and show the importance of supervising opioid use in pediatric patients, especially within the ICU. Thus, the implementation of tools that identify ADEs is useful for a more efficient investigation and recording of events, and for obtaining data to improve patient care and safety. An example of such a tool is the Global Trigger Tool, which consists of prospectively reviewing randomized medical records for triggers (such as naloxone) that may signal adverse events. ${ }^{15}$

Some limitations must be considered in this research. Since it is a retrospective study, the research was based only on documented information in the patients' medical records. In addition, 14 of the analyzed medical records presented incompleteness of information. The most prevalent underlying diseases in the patients were cardiovascular and respiratory, which could have influenced the symptoms that led to naloxone use. In addition, due to severe clinical conditions, patients were taking medications other than opioids that could affect the reported symptoms.

However, according to data from the complete medical records, the opioid-antagonist naloxone was administered when patients had sudden symptoms suggestive of opioid poisoning. Considering that naloxone is indicated to counteract the effects of opioids and that the patients' symptoms reported in the medical records disappeared after the administration of this drug, the episodes identified in this study can be considered as opioid-related ADEs.

\section{Conclusion}

In view of the present study, there was a higher incidence of ADEs with opioids in the Cardiac ICU, as well as a high rate of underreporting of these events at the hospital pharmacovigilance service. In addition, the results suggest that opioidrelated ADEs cause significant harm and risk to critically ill pediatric patients, regardless of the opioid type, the age group or the underlying disease.

This study also warns about the importance of the human factor as a possible cause of ADEs, since the processes of preparation and administration of opioids at pediatric doses are critical stages in which failures may occur, with the consequent adverse events. Finally, the importance of $\mathrm{ADE}$ detection and notification is reinforced, as well as the challenge in managing patient safety in pediatric health institutions.

\section{Funding Source}

This study did not obtain financial support

\section{Contributors}

HO contributed with data collection and interpretation and wrote the article; FAM contributed with data analysis and interpretation and relevant critical review of intellectual content; MCR contributed with the study design; performed data analysis and interpretation. All authors approved final version and are responsible for all work information, ensuring accuracy and completeness of any part of the work.

\section{Conflicts of Interest}

The authors declare no conflicts of interest

\section{References}

1. World Health Organization. Conceptual framework for the international classification for patient safety version 1.1: final technical report. Geneva, Switzerland: World Health Organisation; 2009.

2. Sultana J, Cutroneo P, Trifirò G. Clinical and economic burden of adverse drug reactions. Journal of Pharmacology and Pharmacotherapeutics. 2013; 4(5): 73 . 
3. Parmentier-Decrucq E, Poissy J, Favory R, et al. Adverse events during intrahospital transport of critically ill patients: incidence and risk factors. Annals of intensive care. 2013;3(1):1.

4. Cano FG, Rozenfeld S. Adverse drug events in hospitals: a systematic review. Cadernos de Saúde Pública. 2009; 25: S360-S372.

5. Leendertse AJ, Egberts AC, Stoker LJ, et al. Frequency of and risk factors for preventable medication-related hospital admissions in the Netherlands. Archives of internal medicine. 2008; 168(17):1890-1896.

6. Morimoto T, Gandhi TK, Seger AC, et al. Adverse drug events and medication errors: detection and classification methods. Quality and safety in health care. 2004; 13(4):306-314.

7. Fortuna RJ, Robbins BW, Caiola E, et al. Prescribing of controlled medications to adolescents and young adults in the United States. Pediatrics. 2010; 126(6):1108-1116

8. Institute for Safe Medication Practices. ISMP's list of high-alert medications in acute care centers. 2014. https://www.ismp.org/tools/highalertmedications. pdf. Access in October 242016.

9. Jungquist CR, Karan S, Perlis ML. Risk factors for opioid-induced excessive respiratory depression. Pain Management Nursing. 2011; 12(3):180-187.

10. Chung CP, Callahan ST, Cooper WO et al. Development of an algorithm to identify serious opioid toxicity in children. BMC research notes. 2015; 8(1):1

11. Dahan A, Aarts L, Smith TW. Incidence, reversal, and prevention of opioidinduced respiratory depression. The Journal of the American Society of Anesthesiologists. 2010; 112(1):226-238.

12. Sanborn PA, Michna E, Zurakowski D et al. Adverse Cardiovascular and Respiratory Events during Sedation of Pediatric Patients for Imaging Examinations. Radiology 2005; 237(1):288-294.

13. Herzig SJ, Rothberg MB, Cheung M, et al. Opioid utilization and opióiderelated adverse events in nonsurgical patients in US hospitals. Journal of hospital medicine. 2014; 9(2):73-81.

14. Pawasauskas J, Stevens B, Youssef R, et al. Predictors of naloxone use for respiratory depression and oversedation in hospitalized adults. American Journal of Health-System Pharmacy. 2014; 71(9).

15. Takata GS, Mason W, Taketomo C, et al. Development, testing, and findings of a pediatric-focused trigger tool to identify medication-related harm in US children's hospitals. Pediatrics. 2008; 121(4):e927-e935.

16. Griffin FA, Resar RK. IHI Global Trigger Tool for Measuring Adverse Events (Second Edition). IHI Innovation Series white paper. Cambridge, MA Institute for Healthcare Improvement 2009. http://www.ihi.org. Accessed 03 November 2016.

17. World Health Organization. The Uppsala Monitoring Centre. The Importance of Pharmacovigilance. Safety Monitoring of medicinal products. 2002;48 p.

18. Institute for Innovation and Improvement. The paediatric trigger tool user guide, NHS; 2010. http://bmjopen.bmj.com/content/suppl/2014/07/03 bmjopen-2014-005066.DC1/bmjopen-2014-005066supp2.pdf. Accessed 03 November 2016.

19. Beaudoin FL, Merchant RC, Janicki A, et al. Preventing iatrogenic overdose: A review of in-emergency department opioid-related adverse drug events and medication errors. Annals of emergency medicine. 2015; 65(4):423-431.

20. Nwulu U, Nirantharakumar K, Odesanya R, et al. Improvement in the detection of adverse drug events by the use of electronic health and prescription records: an evaluation of two trigger tools. European journal of clinical pharmacology. 2013; 69(2):255-259.
21. Chidambaran, V., Olbrecht, V., Hossain, M., et al. Risk Predictors of OpioidInduced Critical Respiratory Events in Children: Naloxone Use as a Quality Measure of Opioid Safety. Pain Medicine. 2014; 15(12):2139-2149.

22. Hasan RA, Benko AS, Nolan BM, et al. Cardiorespiratory effects of naloxone in children. Annals of Pharmacotherapy. 2003; 37(11):1587-1592.

23. Yung L, Lee KC, Hsu C, et al. Patterns of naloxone use in hospitalized patients. Postgraduate Medicine. 2016; 1:1-6.

24. Lee LA, Caplan RA, Stephens LS et al. Postoperative Opioid-induced Respiratory Depression A Closed Claims Analysis. The Journal of the American Society of Anesthesiologists. 2015; 122(3):659-665.

25. Resar RK, Rozich JD, Classen D. Methodology and rationale for the measurement of harm with trigger tools. Quality and Safety in Health Care. 2003; 12(2):i39-ii45. 